\title{
PATRIMÔNIO MEIO AMBIENTE E MUSEOLOGIA DE RELAÇÕES: REFLEXÕES SOBRE UM PATRIMÔNIO NO DEVIR
}

\author{
Luisa Maria Rocha
}

\section{RESUMO:}

Reflexão sobre o "Projeto Patrimônio Meio Ambiente" e a "Museologia das Relações", propostas teórico-metodológicas para trabalhar as múltiplas relações deste patrimônio, tanto sob os aspectos dos estados, processos e representações da natureza quanto na imersão destes no âmbito sociocultural. Analisa desafios do tema nos museus, tendo como cenário as preocupações com os processos de degradação do meio ambiente, estes objetos de decisão da sociedade diante das incertezas, riscos e ameaças ambientais. A metodologia foi a análise crítica da passagem da representação estética da natureza para a patrimonial, em particular nas questões de valoração nas cartas e declarações patrimoniais oficiais.

\section{PALAVRAS CHAVE:}

Museu, Museologia das relações, Patrimônio, Meio Ambiente, Ética.

\author{
Environmental Heritage and Museology \\ of Relations: reflections on a heritage in \\ becoming
}

\begin{abstract}
:
Reflection on the "Environmental heritage project" and "Museology of Relations", theoretical and methodological proposals to work the multiple relationships of this heritage, both under the aspects of states, processes and representations of nature as the immersion of these in the sociocultural context. Analyzes theme challenges in museums, against the backdrop of concerns over environmental degradation processes, which they decided in the face of uncertainties, risks and environmental threats. The methodology was the critical analysis the passage of aesthetic representation of nature to the heritage, in particular the valuation issues raised in the official letters and asset declarations..
\end{abstract}

\section{KEYWORDS:}

Museum, Museology of relations, Heritage, Environment, Ethics. 


\section{Introdução}

Em 1992, Jean Davallon, Gerald Grandmont e Bernard Schielle lançaram novos desafios para a Museologia no Simpósio promovido pelo International Council of Museums (ICOM). Estes eram provenientes da necessidade de fundamentos para lidar com um meio ambiente marcado pela dimensão social e por um patrimônio que se ancora no futuro para definir o presente. Se antes os museus trabalhavam com a conservação de um passado cujo valor social (estético, histórico, científico) era reconhecido pelas gerações posteriores e, por isso mesmo, permitiam um olhar mais detalhado sobre aquilo que devemos ou não salvaguardar da destruição, em função de um valor simbólico adquirido, na atualidade, o valor de conservação se volta para o meio ambiente, um objeto no devir que se define mais pela noção de virtual do que potencial ${ }^{2}$, na medida em que sua constituição depende de uma correlação de forças e tendências que influenciam sua consecução.

Assim, se eram as gerações posteriores que definiam o patrimônio da geração anterior, agora, a geração presente tem que assumir a posição de definir o legado ambiental para as gerações futuras. Por isso, os museus encontram-se na difícil tarefa de "tomar posição" ou pelo menos discutir o enfrentamento da conservação de um meio ambiente que se efetiva no devir. Para tal, são necessárias mudanças tanto na sua missão de forma a se integrar nas questões sociopolíticas e ambientais decorrentes do momento em que vivemos quanto nas suas práticas museológicas, de maneira a realmente atuar junto à sociedade promovendo uma reflexão crítica acerca dos diferentes modos de conceber e vivenciar a relação sociocultural do homem com seu meio ambiente. Assim, o papel do museu volta-se também para a formação de uma opinião pública capaz de ser protagonista na tomada de posição no debate social sobre as questões ambientais com vistas ao que foi definido como "Nosso Futuro Comum"3.

No século $X X I$, o patrimônio ambiental ainda nos desafia. Um patrimônio integral, ou mesmo mais recentemente o inclusivo, que se ancora na materialidade representacional de um objeto, não fornece caminhos para tratar as múltiplas dimensões e relações do meio ambiente, que se espraia entre o material e imaterial, entre o tangível e o intangível, entre o meio ambiente e a capacidade do ser humano de atribuir valor e simbolizar cada elemento da natureza de maneira a estabelecer determinadas formas de se relacionar e viver o seu meio, agora eminentemente sociocultural.

Nesse sentido, a abordagem museológica de conservação do patrimônio "meio ambiente" não pode prescindir das formas contingenciais da relação homem-natureza, manifestas nos valores éticos subjacentes à experiência social, que na atualidade é marcada pela diversidade de valores e normas de conduta gerando uma crise de referências para ação no mundo. Assim, a reflexão sobre esta pluralidade de formas de vida se faz importante, uma vez que se pode comprometer as futuras gerações com um modo de vida que ameaça a sustentabi-

2 Os conceitos de potencial e virtual são definidos por Lévy (1996:16) como, respectivamente, aquilo que já está completamente constituído, predeterminado e definido, mas permanece sem existência ou materialidade, e como um complexo problemático, "composto por um nó de tendências, forças e coerções acompanhando situações, acontecimentos, objetos e entidades".

3 Relatório Brundtland é o documento intitulado "Nosso Futuro Comum" de 1987, que define desenvolvimento sustentável. 
lidade do planeta, também se pode eleger um meio como um fim, ou seja, considerando a sustentabilidade como valor supremo de um regime moral e ético.

Dessa maneira, se a conservação é um dos pilares dos museus voltados para a questão ambiental, o patrimônio "Meio Ambiente" encontra na dimensão ética um campo fértil para o trabalho museológico, no qual saberes, práticas e valores se amalgamam e circulam na esfera pública, subsidiando as ações concretas nos contextos de diferentes formas de vida.Ações estas que espelham os diferentes grupos culturais e as formas de conceber e vivenciar a relação com o meio ambiente de determinadas identidades coletivas. $E$, por que não dizer, espelham as formas de valorar e configurar esta relação ou aquilo que podemos nomear um "patrimônio ético".

A gestão museológica desse patrimônio também não pode deixar de lidar com a dupla dimensão material e imaterial, nos seus diferentes planos e fluxos, como no âmbito do objeto, em que prática e representações se mesclam, ou ainda da informação, compreendida tanto como conteúdo objetivado e mensurável quanto como apropriada e ressignificada nos jogos de linguagens das práticas sociais. Não podemos compreender o meio ambiente desarticulado das relações socioculturais, sob o risco de esvaziarmos o patrimônio de seu conteúdo existencial, este oriundo, em particular, do cotidiano e do trabalho.

Assim, as reflexões se direcionam para os caminhos da musealidade do patrimônio "meio ambiente" na sociedade atual, em particular para a constituição de um patrimônio que se define temporal e espacialmente nas diferentes formas de conceber e viver a relação sociedade / meio ambiente.

\section{A Museologia de Relações}

"[...] estabelecer relações entre os universos aparentemente sem pontes." Roland Arpin (1992: 91)

No livro L'environnement entre au Musée, Jean Davallon, Gerald Grandmont e Bernard Schielle, no ano de 1992, tinham como proposta a configuração de uma "Museologia de relações" instituída entre quatro vertentes: o conhecimento, construído pela ciência e tecnologia; as representações sociais, formadas no hibridismo dos discursos dos diferentes atores sociais na esfera pública; a política, protagonista nas tomadas de decisão; e as mídias, pelo tratamento jornalístico nas controvérsias ambientais (I992: |3|-|32). Seu foco era a formação de uma opinião pública capaz de ser protagonista na tomada de posição no debate social sobre as questões ambientais, estas reconstituídas nas suas múltiplas dimensões tendo como eixo a patrimonialização do meio ambiente.

Assim, a Museologia se inscreveria como uma contribuição à recomposição do cimento social ao engajar o museu em três direções: ajudar o público a formar uma visão do patrimônio "verde", propiciar a instauração de uma cidadania e atuar na fronteira dos grupos de pressão.

Entretanto, trabalhar esse patrimônio "verde" impõe desafios aos museus na medida em que este é, ao mesmo tempo, próximo e distante do visitante, em particular, pela invisibilidade de sua natureza profunda proveniente da dinâ- 
mica sistêmica ecológica. Apesar de invisível, esse patrimônio deve ser objeto de decisão da sociedade diante das incertezas, riscos e ameaças ao meio ambiente. Reunindo os processos, os estados e as representações da natureza, a "Museologia de relações" instaura a transição de uma representação estética da natureza para uma patrimonial, ampliando os conceitos de "preservação" e "patrimônio" e redefinindo o papel do museu na "guarda" e "gestão" de um projeto de patrimônio que se ancora nas gerações futuras.

A temática do meio ambiente também requalifica a abordagem tradicional de comunicação dos museus alinhando-se com a mídia, em particular com as técnicas de jornalismo, quando os fatos são reportados de diversas fontes, às vezes contraditórias, na busca por uma "unidade de significação" formada pela trama resultante da relação entre "fatos e heurística" / "informação e contexto" (Davallon et al., 1992: I34). Ao propiciar uma vivência da complexidade das questões ambientais, o museu trabalha as expectativas estruturais da informação pública, compreendendo-as como "um meio de pensar as escolhas".

Cabe ressaltar que o núcleo da Museologia reside na garantia da preservação do patrimônio e, portanto, no projeto patrimônio "meio ambiente" materializado em temas de exposições, de sensibilização, de debates, de mobilização e de legitimação. Nesta direção, os museus devem

[...] repensar a concepção tradicional de sua missão para perpetuar o papel simbólico de guardião do patrimônio que a sociedade o devolveu e que sem isso não existe razão de ser e agir como intérprete de um mundo no devir da preservação antecipando a edificação de um novo relacionamento (Davallon et al., 1992: I34, tradução nossa).

Essa reconfiguração traz outro desafio para a Museologia: trabalhar os cidadãos e o seu meio ambiente buscando o devir de um agente social. Configura-se, então, uma gestão de mobilização social que, a partir desse patrimônio, recoloca o museu como um espaço público capaz de relacionar as dimensões políticas, econômicas e éticas às novas questões ambientais. Estas relações possibilitam, sob o aspecto social, a conexão entre a vida cotidiana das pessoas e a degradação do meio ambiente. Um plano museológico de responsabilidade social, em se tratando de meio ambiente, deve evitar que a responsabilização se restrinja às múltiplas reformulações de uma ideologia individualista dependente da regra da vida de cada indivíduo. Na visão, "a Museologia, como ato de discurso, induz tanto às relações construídas com a natureza quanto às relações construídas com a sociedade (mais precisamente as formações sociais), que normalizam e legitimam as primeiras" (Davallon et al., 1992: I37, tradução nossa).

Nesse caminho, o museu encontra, no tecido social formado pela relação sociedade/meio ambiente, um campo fértil de análise e construção museográfica. $\mathrm{O}$ valor atribuído pela sociedade às práticas e recursos ambientais encontra nos museus a base de construção museográfica que, apesar de apoiar-se no conhecimento científico, tem sua composição atravessada por outros valores e práticas culturais. Na visão de Lima (20I2:45), os processos da "Patrimonialização e da Musealização" de bens simbólicos envolvem os modelos de apropriação teórica e prática através do tratamento dos "planos do tangível (material) e do intangível (imaterial), passíveis de serem interpretados na qualidade de 
referências culturais no tempo-espaço histórico e geográfico". Assim, a relação sociedade/meio ambiente, expressa nos valores e práticas que conformam determinadas formas de vida, pode ser objeto de musealização, por ser referência cultural de diferentes grupos no tempo e no espaço.

O engajamento do museu direcionado para a formação de uma opinião pública permite estabelecer múltiplas relações com base na realidade social, associando os diferentes pontos de visitas e mobilizando recursos para representar e defender o interesse da preservação do patrimônio:

Como ator social de um debate em que ele se coloca, o museu encerra seu status de neutralidade; ele deve ser protagonista. Ele não encarna mais a objetividade do científico, aquelas representações do passado a que havia se acostumado, e evolui sobre o campo destinado a pertencer àqueles que decidem. Por suas escolhas de programação e de discurso, ele toma a palavra como um corpo constituído da vida civil (Davallon et al., 1992: |37-| 38, tradução nossa).

Ao afirmar que as escolhas sociais devem conservar "o espírito da questão do conhecimento", o museu define o lócus do trabalho museológico com seu público, mesclando o seu status cultural e patrimonial:

Os museus descobrem hoje um patrimônio pensado ao futuro. Um patrimônio que, além disso, quebra esse isolamento da instituição museológica - sua reserva - que se tornou tradição, e convida a se associar à força do debate. O museu toma posição (Davallon et al., 1992: I37-I38, tradução nossa).

Assim, o tema meio ambiente transcende o espaço expositivo tornando-se um conceito integrador, o qual subsidia uma reflexão acerca dos valores sobre os quais repousa a sociedade ao tempo em que demanda do museu reconsiderar a sua dinâmica institucional. Repensar os processos museológicos e seus resultados, com foco na relação sociedade e meio ambiente, significa, sobretudo, redistribuir as relações de força no campo de forma a contemplar sua dimensão pública (Davallon et al., 1992:48).

O museu como espaço de sociabilidade se direciona para a prática de uma "Museologia de relações" voltada para dialogar com um cidadão. Esta visão, herdada dos museus de sociedade como o ecomuseu, potencializa-se ao lidar com a temática "meio ambiente", uma vez que esta reenvia e reforça uma relação: a integralidade relacional homem-natureza (Davallon et al. 1992: 203) ou, ainda ampliada, sociedade-meio ambiente.

Somam-se a essa proposta outras apresentadas no Colóquio Museologia e Meio Ambiente, realizado pelo ICOM, em 1990. Destaca-se, pelo seu poder visionário dos rumos tomados pela Museologia, o trabalho de Roland Arpin (1992:91) que define como "sintonizadores" os museus originários da sociedade de comunicação e que têm como princípio "estabelecer relações entre os universos aparentemente sem pontes", trazendo muitas vezes para evidência novas realidades. Como afirma o autor: "Estes museus adotam muito naturalmente uma abordagem temática através de um caminho diacrônico, intercultural e multicomunicacional". Na sua visão, o museu passou, pouco a pouco, da singularidade para a pluralidade e se inscreveu num presente em movimento tanto no tratamento dos assuntos quanto na forma de abordá-los. 
Indo além, acredita-se que os museus "sintonizadores" podem instaurar novos processos de musealização oriundos das múltiplas relações com um real que não apenas dialoga com o passado, o presente e o futuro, mas que, na inevitabilidade de penetrarmos pelas portas da temporalidade, busca nos adensamentos dos fluxos sociais refletir sobre um patrimônio em constante devir.

Ao mencionar a questão ambiental, Roland Arpin (1992) destaca que, apesar da sensibilização para o tema, a sociedade de consumo não mostra evidências de modificações nos hábitos e na cultura. Isto implica dizer que esta questão tem que ser tratada a partir da complementaridade das dimensões política, científica, técnica, econômica e ética. Como afirma o autor:

Como instituição pública o museu se inscreve numa dinâmica - do meio ambiente - onde se encontram conhecimento e ação, o privado e o público, o individual e o coletivo, o singular e o plural. E tudo será à maneira do museu: em respeitar a liberdade do visitante, em privilegiar o conhecimento, em fornecer a justa informação, em utilizar a sua linguagem e seus meios específicos de comunicação, e em colocar a fantasia, que é o inverso a pregar (Arpin, 1992: 139, tradução nossa).

A partir da proposta de Jean Davallon, Gerald Grandmont e Bernard Schielle (1992) e de Roland Arpin (1992), pretendemos caminhar caracterizando algumas das especificidades de um museu que trata do patrimônio "meio ambiente", como objeto da musealização.

\section{Museu e o Patrimônio Meio Ambiente}

"O patrimônio meio ambiente se define no interior da topologia do imaginário que caracteriza a emergência, não mais de uma luta, mas de uma sobrevivência conjunta do homem e da natureza."

Davallon et al. (1992: 80, tradução nossa)

No século $X X I$, as questões ambientais ainda desafiam as abordagens tradicionais de patrimônio dos museus, nas quais lidar com um patrimônio reconhecido com um valor social proveniente do caráter estético, científico ou histórico não apresenta subsídios para tratar o meio ambiente como patrimônio. Davallon et al. (1992) traçaram um mapa das múltiplas conexões entre patrimônio, natureza e sociedade, de forma a possibilitar a reconfiguração das relações homem-meio ambiente como substrato de sua patrimonialização.

A abordagem museológica do patrimônio "meio ambiente" tem um caráter relacional em que se entrecruzam diferentes agentes, configurando de forma contingente a relação sociedade-meio ambiente que, em última instância, tem sua reflexividade manifesta não somente nas suas transformações visíveis, mas, sobretudo no campo social. Neste, como afirma Soares (2008:109), "o meio ambiente é um 'ser social' fundamentalmente híbrido fundado nas amplas representações sociais, um ser de linguagem adquirindo sentido no campo do imaginário".

Esse hibridismo envolve cientistas, especialistas e técnicos que falam sobre as "coisas da natureza", os processos ecológicos, os estados dos recursos naturais, as decisões políticas e normativas, a mídia e as abordagens ambientais, e 
as representações formadas na interação destes diversos agentes. $A$ imbricação destas representações no âmbito da linguagem influencia a forma a partir da qual se pensa o meio ambiente e, por conseguinte, a maneira como $\circ$ tratamos. Sua especificidade a ser trabalhada pelo museu ancora-se na constatação de um sentimento de urgência frente a um "destino coletivo incerto" (Davallon et al., 1992:137-175).

Assim, o papel social dos museus diante da conservação do meio ambiente redireciona as abordagens das coleções científicas biológicas para o âmbito da comunicação, na qual as "coisas da natureza" foram mobilizadas para apresentar as mudanças no meio ambiente de forma a ampliar a compreensão da interdependência da vida e de sua diversidade no planeta.

As coleções e o conhecimento científico a elas associado constituem os lugares do patrimônio da natureza. A estas instituições se acrescentam os jardins botânicos, museus de acervo vivo, com um patrimônio científico composto pela coleção de plantas vivas, de herbários e correlatas, além dos jardins zoológicos e das unidades e centros de conservação da flora e da fauna. Todas estas coleções apresentadas em suas instituições sob a égide das "leis gerais da natureza", ao integrar o patrimônio meio ambiente, inserem-se numa outra lógica, eminentemente relacional, que articula campos de saberes distintos e os apresenta ancorados na sociedade (Davallon et al., I992:4I).

Aqui, mais uma vez, o meio ambiente amplia e consolida uma visão museológica, na qual o patrimônio natural e cultural, material e imaterial, tangível e intangível constitui uma só realidade, indissociável pelas suas mútuas influências, e, por estar ancorado na sociedade, adquire um amálgama social, capaz de constituir uma totalidade, ainda que precária e contingente, que guarda em si as suas singularidades ${ }^{4}$.

Da mesma forma, a emergência do meio ambiente como "mundo invisível" vem atrelada à transformação dos processos inicialmente de degradação do "mundo vivido" (passagem de rodovias, implantação de usinas etc.) para aqueles do "mundo conhecido" (poluição, destruição camada de ozônio, efeito estufa etc.).A complexidade dos processos relacionados ao meio ambiente, tanto aqueles de caracteres biológico e ecológico ainda desconhecidos da ciência quanto aqueles decorrentes dos efeitos da exploração desmedida da natureza, implica um esforço de mediação do museu na sua representação para a sociedade (Davallon et al., 1992:75).

O conhecimento acerca do estado das questões ambientais envolve a mobilização de cientistas, especialistas e técnicos para obtenção de uma avalia-

4 As discussões sobre museu integral e meio ambiente tiveram como fórum inicial os encontros do ICOFOM LAM. Na Mesa-Redonda de Santiago do Chile, realizada pelo ICOM em 1972 , foram definidos, especialmente pelos países latino-americanos, os princípios do museu integral, que contempla a sua integração à vida da sociedade, mas também o seu papel decisivo no conhecimento de seu patrimônio natural e cultural. Segundo Scheiner, (2012, p.19), no texto da Carta de Santiago de 1972 o termo "museu integral" está vinculado ao conceito de "patrimônio integral", construído sobre uma percepção holista do meio ambiente.A autora afirma que, apesar do conceito de Museu Integral estar voltado para a ação comunitária, tal proposta social encontra-se no âmago de todos os museus, qual seja de "aproximar o indivíduo dos processos e produtos da natureza e da cultura". Na Carta de Cuenca publicada noVI Encontro Regional do ICOFOM LAM de 1997 foi definido que "Se considera, por lo tanto, que sólo la fusión de lo tangible y lo intangible constituye lo patrimonio integral". (2006, p. 40). 
ção técnico-científica que delineia questões como água, florestas, clima, poluição, entre outras. Obter informações sobre estes estados constitui uma operação de gestão patrimonial.A gestão tanto de um projeto de meio ambiente inscrito no devir quanto do conhecimento a este associado subsidia a tomada de decisão. Portanto, gestão, conhecimento e tomada de decisão constituem o quadro a partir do qual o meio ambiente é pensado como patrimônio (Davallon et al., 1992:73).

Em seu papel social e comunicacional, o museu agora trabalha a tomada de decisão a partir dos constrangimentos e particularidades políticas, da existência de grupos e estruturas diversas que movem o pensar, o social e os interesses, direcionando esforços para um plano simbólico que promova o diálogo entre o sistema de representação do museu e o imaginário social (Davallon et al., 1992:75).

No campo do imaginário, trata-se de identificar as representações sociais de uma temática, suas associações e oposições, de forma a ancorar o patrimônio no âmbito social. As representações de recursos naturais finitos se contrapõem aos modelos econômicos predatórios ou ainda aparecem associados ao conceito de sustentabilidade reforçando a busca de uma relação mais "equilibrada" com o meio ambiente. Sem dúvida, a lógica relacional advinda da Ecologia propicia uma abordagem que privilegia as complementaridades entre os diferentes domínios, mostrando a interdependência entre homem (cultura e sociedade) e seu meio ambiente (meio natural, construído e simbólico), possibilitando reconfigurar a abordagem do museu na direção de uma Museologia das relações sociedade-meio ambiente.

É importante ressaltar que o patrimônio meio ambiente difere daquele dos parques naturais (patrimônio natural) e do ecomuseu (patrimônio social e simbólico), mas ambos possibilitaram a passagem de uma representação estética da natureza para uma representação patrimonial do meio ambiente. Esta passagem também ocorreu nas cartas e declarações patrimoniais oficiais reconhecidas internacionalmente pela Organização das Nações Unidas para a Educação, a Ciência e a Cultura (Unesco) e pela União Internacional para Conservação da Natureza e Recursos Naturais (IUCN).

Se na Conferência Geral da Unesco (Recomendação de Paris), realizada em 1962, a preservação da natureza tinha como fundamento atender às necessidades humanas em seus aspectos estéticos, numa clara associação com o monumento cultural, na Assembleia Geral das Nações Unidas, em 1972, o foco passou à proteção e melhoria do meio ambiente com vistas ao bem-estar dos povos. Na visão de Bezerra (2009:6), a última atribuiu maior relevância à natureza como forma de garantir as condições para o desenvolvimento humano, sem prejuízos dos sistemas naturais, para as gerações presente e futura.

Complementarmente, a Conferência do Meio Ambiente (CNUMA), realizada em Estocolmo em 1972, teve a preocupação de garantir a sobrevivência dos ecossistemas em prol da sobrevivência física e social da humanidade (Bezerra: 2009). Nesse mesmo ano foi criado o United Nations Environment Programme (UNEP) e seu Programa das Nações Unidas para o Meio Ambiente (PNUMA) para atuar como catalisador de ações em benefício do meio ambiente, além de promover a interação de cientistas, políticos, líderes sociais e formadores de opinião em geral. 
A Conferência Geral da UNESCO, realizada em Paris no ano de 1972, reforçou a Carta de Estocolmo, além de propor a proteção, conservação e valorização do patrimônio mundial cultural e natural. Esta concepção integrada do patrimônio nos desperta para uma gama de valores atribuídos ao elemento patrimonial como o histórico, artístico, estético, científico, natural e cultural. A estes valores outros mais são associados, como no Relatório Brundtland (Nosso Futuro Comum), em 1987, quando o conceito de desenvolvimento sustentável ${ }^{5}$ passa a estar associado à sustentabilidade, como um valor a ser considerado frente à interdependência do binômio meio ambiente/desenvolvimento. Como afirma Bezerra (2009:8), o teor das cartas e documentos das Nações Unidas "demonstrou a crescente tensão entre o modelo de desenvolvimento econômico hegemônico e a proteção da natureza”, em particular, ao manifestar a preocupação com o bem-estar das gerações futuras diante do agravamento dos problemas socioambientais. Assim, a natureza, na qualidade de um bem patrimonial, contempla em si "valores intrinsecamente naturais e os socialmente a ela atribuídos".

O valor atribuído à natureza pelo homem tem em si o fundamento das suas ações e comportamentos em relação ao meio em que vive. $O$ valor, além de ser o elemento de mediação e de definição do tipo de relação do homem com a natureza, também significa um fundamento para a questão ética manifesta na conexão entre razão e ação. Assim, o valor fundamenta os processos de musealização e sua origem advém do próprio campo cultural, uma vez que este se refere "à totalidade da vida social" quando diferencialmente qualificada (Menezes, 2009:29).

Pode-se tomar tal afirmativa para um objeto ou artefato que pela atribuição de valor se destaca de outros na totalidade da vida social. Assim, trabalhar com objetos ou práticas envolve descobrir as propriedades derivadas da sua natureza material mobilizadas pelas sociedades, grupos sociais e comunidades de forma a colocar em ação suas ideias, expectativas e significados que configuram em suma seus valores. Como propõe Menezes (2009:32) "a matriz de sentidos, significações e valores não está nas coisas em si, mas nas práticas sociais". Por isso, atuar no campo cultural é se defrontar com a problemática do valor. Ou como afirma Menezes (2009:29), cultura como forma de qualificar diferencialmente (pelo sentido, pela significação, pelo valor) qualquer instância, tempo, objeto ou prática.

É possível ainda compreender patrimônio como um conjunto de valores que cada sociedade, em seu tempo e lugar, produz para si mesma, e qualifica um tipo de relação com o meio ambiente manifesto numa ética que subsidia a razão e a ação. Conforme esclarecem Borges e Campos (2012: I | 4, I I6, I I8), "o patrimônio, por ser valor e categoria de pensamento, é, por excelência, intangível ou simbólico-cultural" uma vez que constitui um atributo social-histórico, e que pode ser relacionado a determinadas formas de viver e conceber as nossas relações com o mundo que nos cerca. $E$, nesse sentido, o valor também pode fundamentar processos de musealização que tenham como objeto as diferentes formas de conceber e viver o meio ambiente e as suas representações.

5 Definição: "O desenvolvimento que satisfaz as necessidades do presente sem comprometer as habilidades das futuras gerações de satisfazerem suas necessidades". 
A conservação do patrimônio ambiental está submetida ao conjunto de diretrizes e procedimentos de gestão adotados pelo sistema global de conservação patrimonial da Unesco e pelos órgãos gestores do patrimônio natural e cultural - IUCN e International Council on Monuments and Sites (Icomos). A sua consolidação adveio da Convenção do Patrimônio Cultural e Natural (1972), quando a Unesco montou um sistema mundial de gestão patrimonial, no qual foi cunhada a Declaração de Significância para avaliação dos candidatos a Patrimônio Mundial. Esta tem como referência o conceito de significância cultural: "valor estético, histórico, científico, social ou espiritual para as gerações passada, atual ou futura".

Com relação ao patrimônio natural, a Carta de Burra (1999:4) define "significado natural" como "a importância dos ecossistemas, da biodiversidade e da geodiversidade, pelo valor de sua existência, ou em termos do seu valor científico, social, estético e de suporte de vida para as gerações atual e futura".

Na Conferência das Nações Unidas sobre o Meio Ambiente, em Estocolmo, o estabelecimento de princípios comuns através da Declaração sobre o Ambiente Humano apontou, por diversas vezes, a responsabilidade humana na preservação dos recursos naturais da Terra, tais como "preservar e administrar ponderadamente o patrimônio representado pela flora e pela fauna silvestres, bem como pelo seu habitat" (Princípio 4) e, ainda, a responsabilidade "com a proteção e melhoria do meio, em toda a sua dimensão humana” (Princípio 19).

Esses princípios evidenciam o valor intrínseco dos bens naturais, conforme reafirma Bezerra (2010:166), o meio ambiente, além do "valor de uso", tem um "valor de existência", que significa que "o mundo não humano tem interesses e relevância moral independente de sua utilidade social".

$\mathrm{Na}$ compreensão de Jeremy Roxbee Cox (1997:103-II8 apud Bezerra: 2009), o valor de existência está relacionado tanto ao seu valor intrínseco quanto ao valor extrínseco entendido como uma postura moral. Nesse sentido, difere do âmbito econômico, em que o entendimento do valor é aplicado numa visão monetária do meio ambiente, na qual se refere à soma dos benefícios proporcionados para quem o avalia sob a ótica de suprir necessidades de satisfação e usufruto. $\bigcirc$ valor de existência por razões de ordem moral pode ser relacionado à proteção do meio ambiente para as futuras gerações. Assim, a relevância reside em que as coisas do meio ambiente têm um valor intrínseco inserido na classe de valor moral.

Essa compreensão constitui um primeiro passo para consolidar o entendimento da proteção do patrimônio cultural e natural integrados, na medida em que contempla outros valores para além dos já consagrados - o estético, 0 histórico, o científico, o social ou o espiritual -, como os processos ecológicos e os da paisagem ${ }^{6}$. Este último é capaz de exprimir a relação de sentido que uma sociedade estabelece com o espaço e a natureza (Berque, 2004:84-85). Um segundo passo foi o relatório da Comissão Mundial para o Meio Ambiente e Desenvolvimento (CMMAD), também conhecida como Comissão de Brundtland

6 Augustin Berque afirma: "A paisagem é uma marca, pois expressa uma civilização, mas é também uma matriz porque participa dos esquemas de percepção, de concepção e de ação - ou seja, da cultura - que canalizam, em certo sentido, a relação de uma sociedade com o espaço e com a natureza e, portanto, a paisagem do seu ecúmeno" (Berque apud Corrêa, Roberto Lobato; Rosendahl, Zeny, 2004:84-85). 
(1987), quando foi exposta a definição:"O desenvolvimento sustentável é aquele que atende as necessidades do presente sem comprometer as possibilidades de as gerações futuras atenderem suas próprias necessidades".

Assim,"Pensar integral" envolve pensar com equidade as relações passado e futuro a partir das questões colocadas no presente, e assumir a responsabilidade pelos nossos atos, ao menos em relação à proteção ambiental e equidade social, ou tal qual foi afirmado no relatório Nosso Futuro Comum: "A pobreza já pode ser considerada como um problema ambiental e como um tópico fundamental para a busca da sustentabilidade".

Na Rio 92, a Convenção sobre a Diversidade Biológica objetivou a conservação da biodiversidade, o uso sustentável de seus componentes e a repartição justa e equitativa dos benefícios provenientes dos recursos genéticos. Apontando para a importância do patrimônio genético, a Convenção possibilita a ampliação do que é patrimônio e seu imbricamento natural e cultural.

Compreende-se que tanto as cartas patrimoniais quanto as convenções e relatórios do meio ambiente entrelaçam princípios como equidade entre gerações, valor de existência, incerteza e precaução na relação com o patrimônio natural. Estes princípios transcendem a tipologia específica do patrimônio para se referirem à sua integralidade, a qual pressupõe:

A equidade entre gerações significa assegurar que as condições de saúde, diversidade e produtividade sejam mantidas pelas presentes gerações em benefício das futuras; o princípio do valor de existência significa que os organismos vivos, os processos terrestres e os ecossistemas possuem um valor que estão além do caráter social, econômico ou cultural dos seres humanos. O princípio de incerteza quer dizer que o nosso conhecimento acerca do patrimônio natural e dos processos que afetam são incompletos e que a significância potencial ou valor do patrimônio natural permanece desconhecido por conta desse estado de incerteza do conhecimento; e o princípio de precaução significa que, onde há ameaça ou potencial ameaça de sério ou irreversível dano ambiental, a falta de certeza científica não poderá ser usada como uma razão para adiar as medidas de prevenção contra a degradação ambiental. (Bezerra, 2010: 168-169)

Essa passagem de um patrimônio natural para um patrimônio pensado na sua integralidade pode ser visualizada nos quadros abaixo apresentados.

O quadro I refere-se às Cartas e declarações patrimoniais sob o ponto de vista da passagem de uma preservação da natureza pautada pelo caráter estético para uma que se apoia em princípios éticos e pragmáticos. No quadro 2 , as Declarações e convenções sobre meio ambiente ampliam o conceito de natureza na medida em que inserem as suas relações ecossistêmicas e para além destas entrelaçam a dimensão econômica, social e cultural como forma de conceber e vivenciar a relação sociedade-meio ambiente.

Percebe-se, assim, que a partir da Carta de Burra, o patrimônio natural ganhou novas cores e tonalidades geradas por uma paleta social. Do valor da existência aos valores sociais, este patrimônio perde as suas fronteiras entre natural e cultural, e ganha novos contornos. 


\section{Quadro I: Cartas e declarações patrimoniais}

\begin{tabular}{|c|c|c|c|}
\hline Período & Local & Especificação & Observações \\
\hline 1931 & Atenas & Carta de Atenas & $\begin{array}{c}\text { Definição do patrimônio pelas relações do espaço, da paisagem } \\
\text { e da trama urbana adjacentes. Foco nas relações entre } \\
\text { disciplinas. }\end{array}$ \\
\hline \multirow[t]{2}{*}{1962} & \multirow[t]{2}{*}{ Paris } & $\begin{array}{l}\text { Conferência Geral da Unesco - } \\
12^{\circ} \text { sessão }\end{array}$ & $\begin{array}{c}\text { Preservação da natureza tinha como fundamento atender as } \\
\text { necessidades humanas em seus aspectos estéticos. }\end{array}$ \\
\hline & & Recomendação de Paris & $\begin{array}{c}\text { Proteção e salvaguarda dos sitios e territórios aos quais eles } \\
\text { pertencem. }\end{array}$ \\
\hline \multirow[t]{2}{*}{1964} & \multirow[t]{2}{*}{ Veneza } & Carta de Veneza & \multirow{2}{*}{$\begin{array}{l}\text { Monumentos - Conservação depende de sua função "útili" a } \\
\text { sociedade. Compreende a criação arquitetônica, sitio urbano } \\
\text { ou rural .Estende-se às grandes criações e as modestas, com } \\
\text { uma significação cultural }\end{array}$} \\
\hline & & $\begin{array}{l}2^{\circ} \text { Congresso Internacional de } \\
\text { Arquitetos e Técnicos dos } \\
\text { Monumentos Históricos }\end{array}$ & \\
\hline \multirow[t]{2}{*}{1964} & Paris & $\begin{array}{l}\text { Conferência Geral da Unesco - } \\
13^{\circ} \text { sessão } \\
\end{array}$ & $\begin{array}{l}\text { Definição de bens culturais. Questão patrimonial alcança o } \\
\text { mundo. }\end{array}$ \\
\hline & & $\begin{array}{c}\text { Criação do Icomos - Conselho } \\
\text { Internacional de Monumentos e } \\
\text { Sitios }\end{array}$ & $\begin{array}{l}\text { Unifica as preocupações mundiais com o patrimônio } \\
\text { arquitetônico. }\end{array}$ \\
\hline \multirow[t]{2}{*}{1970} & \multirow[t]{2}{*}{ Brasil } & Compromisso de Brasilia & $\begin{array}{l}\text { Brasil integra-se a discussão dos problemas do patrimônio } \\
\text { cultural }\end{array}$ \\
\hline & & Iphan & $\begin{array}{c}\text { O Departamento do patrimônio histórico e Artistico Nacional } \\
\text { passa ao status de Instituto, responsável pela proteção do } \\
\text { patrimônio nacional. }\end{array}$ \\
\hline \multirow[t]{4}{*}{1972} & \multirow[t]{4}{*}{ Paris } & $\begin{array}{c}\text { Convenção Relativa à Proteção } \\
\text { do Patrimônio Mundial, Cultural } \\
\text { e Natural }\end{array}$ & $\begin{array}{l}\text { Patrimônio passa a contemplar "lugares notáveis", com valores } \\
\text { excepcionais etnológico, estético, histórico ou antropológico. }\end{array}$ \\
\hline & & & $\begin{array}{l}\text { Proteção, conservação e valorização do patrimônio mundial } \\
\text { cultural e natural. }\end{array}$ \\
\hline & & $\begin{array}{l}\text { Conferência Geral da Unesco - } \\
17^{\circ} \text { sessão }\end{array}$ & Sistema mundial de gestão patrimonial. \\
\hline & & & $\begin{array}{l}\text { Proteção e melhoria do meio ambiente com vistas ao bem- } \\
\text { estar dos povos. }\end{array}$ \\
\hline 1980 & Austrália & $\begin{array}{l}\text { Atualização da Carta de Burra } \\
\text { Icomos }\end{array}$ & $\begin{array}{l}\text { Patrimônio Mundial passa a basear-se Declaração de } \\
\text { Significância, sendo significado cultural definido como o valor } \\
\text { estético, histórico, cientifico ou social de um bem para } \\
\text { gerações passadas, presentes ou futuras. }\end{array}$ \\
\hline \multirow[t]{3}{*}{1985} & \multirow[t]{3}{*}{ México } & \multirow[t]{3}{*}{ Declaração do México } & Patrimônio inclui bens imateriais \\
\hline & & & $\begin{array}{l}\text { Conceito de cultura ampliado pela Antropologia: toda a } \\
\text { manifestação do homem que venha a gerar identidade. }\end{array}$ \\
\hline & & & Patrimônio cultural inclui a paisagem cultural \\
\hline \multirow[t]{2}{*}{1992} & \multirow[t]{2}{*}{ Rio de Janeiro } & Carta do Rio & \multirow{2}{*}{$\begin{array}{l}\text { Reafirma a declaração de Estocolmo, apresenta principios } \\
\text { sobre meio ambiente e desenvolvimento sustentável. }\end{array}$} \\
\hline & & $\begin{array}{c}\text { Conferência geral das Nações } \\
\text { Unidas sobre meio ambiente e } \\
\text { desenvolvimento. }\end{array}$ & \\
\hline 1996 & Austrália & $\begin{array}{l}\text { Carta do Patrimônio Natural } \\
\text { Australiano }\end{array}$ & $\begin{array}{l}\text { Significado natural - "a importância dos ecossistemas, da } \\
\text { biodiversidade e da geodiversidade, pelo valor da sua } \\
\text { existência, ou em termos do seu valor cientifico, social, estético } \\
\text { e de suporte de vida para as gerações atual e futuras" (2002:9) }\end{array}$ \\
\hline \multirow[t]{2}{*}{1997} & \multirow[t]{2}{*}{ Mar del Plata } & Documento do Mercosul & Integração cultural. \\
\hline & & $\begin{array}{c}\text { Carta de Mar del Plata sobre } \\
\text { patrimônio intangivel }\end{array}$ & $\begin{array}{l}\text { Registro, catalogação, estudo e difusão do patrimônio } \\
\text { intangivel. }\end{array}$ \\
\hline 2004 & & $\begin{array}{c}\text { Carta do Patrimônio Natural no } \\
\text { Brasil }\end{array}$ & $\begin{array}{l}\text { Preservação do patrimônio natural a partir de duas vertentes: } \\
\text { ética e pragmática. }\end{array}$ \\
\hline
\end{tabular}

Fonte: elaborado pela autora (20I2) 


\section{Quadro 2: Declarações e convenções sobre meio ambiente}

\begin{tabular}{|c|c|c|c|}
\hline Período & Local & Especificação & Observações \\
\hline \multirow[t]{3}{*}{1972} & \multirow[t]{3}{*}{ Estocolmo } & $\begin{array}{c}\text { Declaração de Estocolmo } \\
\text { sobre o ambiente } \\
\text { humano }\end{array}$ & $\begin{array}{l}\text { UNESCO amplia a abrangência do patrimônio } \\
\text { para o meio ambiente natural. }\end{array}$ \\
\hline & & $\begin{array}{l}\text { Assembléia Geral das } \\
\text { Nações Unidas }\end{array}$ & Melhoria da qualidade de vida e meio ambiente. \\
\hline & & $\begin{array}{l}\text { Conferência do Meio } \\
\text { Ambiente (Cnuma) }\end{array}$ & $\begin{array}{l}\text { Preocupação foi garantir a sobrevivência dos } \\
\text { ecossistemas em prol da sobrevivência física e } \\
\text { social da humanidade. }\end{array}$ \\
\hline 1972 & & $\begin{array}{l}\text { Criação do Programa das } \\
\text { Nações Unidas para o } \\
\text { Meio Ambiente (Pnuma) }\end{array}$ & $\begin{array}{c}\text { Catalisador de ações em benefício do meio } \\
\text { ambiente, além de promover a interação de } \\
\text { cientistas, políticos, líderes sociais e formadores } \\
\text { de opinião em geral }\end{array}$ \\
\hline 1987 & & $\begin{array}{l}\text { Relatório Brundtland } \\
\text { (Nosso Futuro Comum) }\end{array}$ & $\begin{array}{c}\text { o conceito de desenvolvimento sustentável } \\
\text { "o desenvolvimento que satisfaz as necessidades } \\
\text { do presente sem comprometer as habilidades das } \\
\text { futuras gerações de satisfazerem suas } \\
\text { necessidades" }\end{array}$ \\
\hline 1985 & Viena & Convenção de Viena & Proteção da camada de ozônio \\
\hline \multirow[t]{5}{*}{1992} & \multirow[t]{5}{*}{$\begin{array}{l}\text { Rio de } \\
\text { Janeiro }\end{array}$} & $\begin{array}{c}\text { Conferência das Nações } \\
\text { Unidas sobre o Meio } \\
\text { Ambiente e } \\
\text { Desenvolvimento - Rio } 92\end{array}$ & $\begin{array}{c}\text { Avaliação das ações dos países na promoção da } \\
\text { Proteção ambiental desde a Conferência de } \\
\text { Estocolmo de } 1972 .\end{array}$ \\
\hline & & $\begin{array}{l}\text { Declaração do Rio sobre } \\
\text { Meio Ambiente e } \\
\text { Desenvolvimento }\end{array}$ & $\begin{array}{l}\text { Carta com princípios para estabelecer um novo } \\
\text { estilo de vida que propicie a proteção dos } \\
\text { recursos naturais e a busca do desenvolvimento } \\
\text { sustentável e de melhores condições de vida para } \\
\text { todos os povos. }\end{array}$ \\
\hline & & Agenda 21 & $\begin{array}{c}\text { Plano de compatibilização entre desenvolvimento } \\
\text { econômico e proteção ambiental }\end{array}$ \\
\hline & & $\begin{array}{c}\text { Convenção sobre } \\
\text { Diversidade Biológica - } \\
\text { CDB }\end{array}$ & $\begin{array}{c}\text { Conservação da diversidade biológica, a utilização } \\
\text { sustentável de seus componentes e a repartição } \\
\text { justa e equitativa dos benefícios derivados da }\end{array}$ \\
\hline & & $\begin{array}{l}\text { Convenção sobre Mudança } \\
\text { do Clima }\end{array}$ & \\
\hline 1994 & França & $\begin{array}{l}\text { Convenção das nações } \\
\text { unidas }\end{array}$ & Combate a desertificação \\
\hline 1997 & Japão & Protocolo de Kioto & $\begin{array}{c}\text { compromisso para a redução da emissão dos } \\
\text { gases que agravam o efeito estufa. }\end{array}$ \\
\hline 2000 & Colômbia & Prototcolo de Cartagena & $\begin{array}{c}\text { Biosegurança - disciplina questões envolvendo } \\
\text { estudo, a manipulação e o transporte de } \\
\text { organismos geneticamente modificados. }\end{array}$ \\
\hline
\end{tabular}


Na visão de Lucie Sauvé (2003:4), trabalhar esse patrimônio nos museus envolveria mapear uma rede de relações a partir de um conjunto de realidades complementares: a natureza (apreciada, respeitada e preservada), os recursos naturais (administrados e compartilhados), os problemas (resolvidos), o sistema de relações (para a tomada de decisão) com vistas à criação de um projeto ético-comunitário com o qual possamos nos comprometer. Esse patrimônio, então, passa a ser visto como uma construção social, um processo de legitimação histórica baseado numa síntese simbólica de valores oriundos do campo social que contribuem para um sentido de pertença e de identificação de um coletivo social.

O patrimônio ambiental é compreendido por Davallon et al. (I992:69-70) como um projeto universalista do patrimônio "meio ambiente" constituído a partir de dois movimentos complementares: o deslocamento do olhar do objeto-patrimônio para o projeto-patrimônio e do status do conhecimento sobre o patrimônio para o conhecimento como patrimônio. No primeiro, o patrimônio se define como "patrimônio em projeto", quando o processual ganha juridicamente o status de patrimônio na medida em que são potências na marcha do devir. No segundo, o conhecimento de um coletivo adquire a importância e a categoria de patrimônio por se constituir em parte integrante do "projeto" ou por ser em si caracterizado como tal.

Nesse caminho, a dimensão jurídica e a dimensão cognitiva asseguram a universalização do patrimônio pelo uso normativo do termo que o define como um conjunto de regras a serem respeitadas. A especificidade do patrimônio "meio ambiente" é dada pela salvaguarda de uma vida que ainda está por vir, ou melhor,"O caso do meio ambiente é singular em sendo virtual: ele pertence aos vivos atuais, mas tem seu sentido de patrimônio ao olhar aqueles que virão após eles" (Davallon et al.: 1 992:71 -72, tradução nossa).

$\mathrm{Na}$ atualidade, Eric Dorfmann e Janet Carding (2012:172-173) afirmam que a atribuição de valor para as várias formas de patrimônio é o cerne do princípio norteador da conservação das convenções da Unesco. Ao analisar o patrimônio natural intangível, os autores evidenciam a importância tanto de um mundo natural a ser conservado quanto de um conhecimento associado que o qualifica e através do qual o patrimônio pode ser valorado como projeto de futuro. Mais uma vez, projeto de futuro e conhecimento se associam para pensar o patrimônio meio ambiente.

$\mathrm{Na}$ visão dos autores, durante muito tempo, a conservação em torno do mundo natural esteve baseada em valores intrínsecos, em vez de ter como base as suas relações com os seres humanos. Entretanto, o princípio do patrimônio tem como base a valoração atribuída pelos seres humanos, motivo pelo qual se requer trabalhar as conexões do mundo natural com os fenômenos intangíveis das inter-relações humanas. Por isso, ao propor uma definição para o patrimônio natural intangível, os autores se reportam às "forças ambientais" como as que proporcionam as bases de criação das interações entre entidades biológicas e os seres e comunidades humanas. Estas interações, compreendidas sob o ponto de vista dos marcos legais e do desenvolvimento sustentável, asseguram um mundo natural para as futuras gerações, no qual a dimensão humana estaria incluída como elemento integral do patrimônio natural intangível, "sem a qual 
seria difícil avaliar se um fenômeno é ou não digno de preservação" (Dorfmann; Carding, 2012:172-173). É esta noção de valor que nos permite desenvolver um critério de conservação, uma vez que para diferentes autores o valor da natureza é em si um fenômeno cultural.

Dorfmann e Carding (2012:I73) apontam ainda a necessidade de explorar as conexões éticas entre o patrimônio natural intangível e o conceito de bem-estar, remetendo claramente para as questões relacionadas a meio ambiente e qualidade de vida.

\section{Por um patrimônio ético}

"O passado bate à porta, o futuro à janela e o presente descobre que não dispõe de solo para ficar de pé."

François Hartog (1996)

Quais os caminhos para uma "Museologia de relações" com foco na relação sociedade-patrimônio ambiental? Quais os caminhos para objetivação desse patrimônio no museu? Quais os caminhos para se refletir sobre a musealização do patrimônio ético?

Essas questões, longe de serem respondidas neste texto, constituem apenas um ponto de chegada e de partida para direcionar nossos esforços e trabaIho na busca por uma museologia que tem como desafio um futuro ambiental alarmante que caminha em nossa direção e demanda repensar as relações da sociedade com o meio ambiente, que somos e sem o qual não sobreviveremos.

Nesse sentido, buscamos uma reflexão e um debate sobre os caminhos para constituição de um patrimônio ético que se define temporal e espacialmente na relação homem-meio ambiente e tem como horizonte aberto a musealização das "formas de vida" que legitimam, em última instância, a razão ética de como se deve viver.

\section{O patrimônio como indício de crise}

$\mathrm{Na}$ atualidade, a forma do entrelaçamento entre tempo e espaço está centrada no presente e se desenvolve em função de seu crescimento e da sua evidência onipresente. Este horizonte de um presente ampliado, hipertrofiado, teve como alimento as exigências de uma sociedade de consumo, na qual o conhecimento científico, as inovações tecnológicas e a voracidade das mídias tornaram as "coisas e os homens cada vez mais obsoletos" (Hartog, I996: I35; 2006:26I).

Nesse contexto, François Hartog (2006:26I-265) redefine "memória" e "patrimônio" como indícios de nossa relação com o tempo, ou ainda, formas diversas de traduzir, refratar, seguir, contrariar a ordem do tempo. Se vivemos entre esquecimento e memória, numa aceleração do tempo, no qual o que se produz hoje já é pensado como histórico, o vivido no presente "tem a pretensão de ser seu próprio horizonte: sem passado sem futuro, ou a gerar seu próprio passado e seu próprio futuro" (Hartog, 1996:137; 2012). 
Nesse desejo de texturização, o patrimônio se liga ao território e à memória, os quais "operam um e outro como vetores da identidade". Esses vetores apontam para uma identidade em busca dela mesma, que tende a se apagar e por isso mesmo precisa ser inventada. Essa invenção se manifesta na produção da memória "por meio do patrimônio, do arquivo, do museu, do testemunho, da filmografia" e encontra-se na busca de raízes e identidades, na conservação de "regimes de vida" através de objetos, monumentos, espécies, paisagens e, a partir dos anos 1980, dos ecossistemas. "Nesta acepção, o patrimônio define menos o que se possui, o que se tem e se circunscreve mais ao que somos, sem sabê-lo, ou mesmo sem ter podido saber" (Hartog, 2006:266).

$\mathrm{Na}$ qualidade de testemunha das incertezas ou de uma "crise" da ordem presente do tempo, o patrimônio aponta para um sinal de ruptura, de "brecha" no tempo, que nele reconhece "uma maneira de viver as cesuras" pela produção de semióforos. $O$ patrimônio se inscreve no âmbito da comemoração, o qual marca a distância temporal entre presente e passado, enquanto trabalha sobre a memória no plano de uma coletividade ("co-memorar"): o "presentismo" possibilita a propagação de lugares destinados a estabelecer "a ligação entre o plano visível e o invisível” (Nicolazzi, 2010:243-244).

Na visão de Hartog (2006:268), o patrimônio contemporâneo expandiu enormemente seu campo de abrangência. Dos espaços urbanos ao meio ambiente, do patrimônio nacional ao patrimônio universal da humanidade, dos objetos culturais aos elementos genéticos - "tudo seria patrimônio ou suscetível de tornar-se".

Na perspectiva de Choay (200I:240), essa “inflação patrimonial” levou a um grande aumento de bens considerados oficialmente como patrimônio, uma vez que para a sociedade os objetos e monumentos do passado refletiam a nossa identidade humana, ou como afirma a autora:"o patrimônio histórico parece fazer hoje o papel de um vasto espelho no qual nós, membros das sociedades humanas do fim do século XX, contemplaríamos a nossa própria imagem”.

Tal expansão também é um reflexo da aceleração do tempo, um instantâneo em que o tempo se torna palpável, mesmo que seja no trânsito que segue do presente para o presente. Segundo Hartog (1997:15), esse "presentismo", a partir dos anos 80 , descobre-se em busca...

[...] preocupado com a conservação (de monumentos, de objetos, de modos de vida, de paisagens, de espécies animais) e ansioso pela defesa do meio ambiente [...]. Como se desejasse preservar, de fato reconstituir, um passado já desaparecido ou a ponto de apagar-se, sem volta.

O futuro como uma perspectiva surge com a recente preocupação com a conservação e instaura um novo fluxo que transita agora do futuro para o presente, adquirindo um significado próprio que contrasta com a comemoração. Ao instituir uma nova forma de lidar com o tempo, em que as solicitações do presente devem ser submetidas ao valor da conservação, estabelece-se um “seguro" contra os próprios prognósticos deste futuro (Hartog, 2006:269).

Ao estabelecer o valor "conservação" como o parâmetro para as solicitações do presente, estamos criando um novo valor na categoria do pensamento 
patrimonial $^{7}$ que atribui à conservação a função de coesão social e articulação da identidade da sociedade do presente. Sem dúvida, o conceito antropológico de cultura, ao qual se refere Gonçalves (2009:30), possibilita ancorar nas relações sociais e simbólicas o olhar patrimonial, não somente sob o ponto de vista dos bens materiais e tangíveis, mas, sobretudo daqueles de caráter imaterial e intangível, que se encontram no campo dos significados sociais, ainda que nosso objeto seja as relações sociedade-meio ambiente.

Essas categorias "desmaterializadas" têm sua substância definida e assegurada na Constituição Federal de 1988, no Artigo 216, como "as formas de expressão" e "os modos de criar, fazer e viver", entre outros. Percebe-se, assim, a importância dos significados e sentidos elaborados nas relações sociais até mesmo na atribuição de valores que guiam as dimensões temporais e espaciais do patrimônio.

No bojo do valor conservação, o mesmo crescimento ocorreu no patrimônio ambiental, agora incluindo desde as dimensões materiais dos recursos naturais, com a criação de áreas protegidas como as unidades de conservação, até aquelas de caráter imaterial como o conhecimento tradicional associado às plantas. Na qualidade de um bem intangível e transitório, o conhecimento acerca do meio ambiente adquire maior valorização quando associado a um patrimônio material, como um recurso natural. Se for certo que o conhecimento intangível constitui um aspecto integral do significado de patrimônio, é igualmente certo que o bem intangível, representado pelo meio ambiente, é dinâmico e forma "parte de uma conexão cultural viva existente entre passado e futuro que os modifica ao longo do tempo" (Decarolis, 2000:5).

Esse valor conservação também requalifica o referencial de responsabilidade da sociedade do presente. Esta assume a responsabilidade de refletir sobre a dimensão do patrimônio ambiental que se encontra à nossa disposição, menos em função de nós mesmos e do sentimento de perda, que em função das gerações futuras e do sentimento de continuidade do que ainda resta a ser conservado. Mais uma vez, perda e continuidade constituem dialeticamente o sentido da categoria patrimônio.

Compreendemos, tal como Hartog (2006:268), que na atualidade a noção de patrimônio busca a permeabilidade e o diálogo com as práticas sociais, numa tentativa de mantê-lo vivo, quer seja material ou imaterialmente:"Deseja-se museificar, mas mantendo vivo, ou melhor, revitalizar reabilitando. Ter um museu, mas sem o fechamento do museu: aqui ainda, um museu 'fora dos muros'? Um museu propriamente de sociedade, senão um museu social”.

Voltando-se para "lugares" capazes de construir uma identidade em torno da circulação, o que chamaremos um adensamento transitório de fluxos de sentido, o patrimônio se multiplica para dar conta dos processos e relações de sentido do homem com seu meio ambiente.

Na visão de Hartog (2006:268), as frentes abertas por um patrimônio material e imaterial se ampliam:

7 Na visão de Gonçalves (2009), o patrimônio é uma categoria do pensamento das sociedades.A valoração de um bem advém dos processos socioafetivos de uma comunidade frente à sua função social de articulação da identidade. 
[...] o'patrimônio cultural protegido',o'patrimônio cultural de proximidade' (este 'tecido conjuntivo' do território nacional), o 'patrimônio natural' (que compreende a 'noção de paisagens'), o 'patrimônio vivo' (as raças animais e espécies vegetais), o 'patrimônio imaterial' (com os savoir-faire tradicionais, as tradições populares, o folclore). $\bigcirc$ patrimônio genético já frequente na mídia e o patrimônio ético a começar a entrar.

Nessas frentes abertas, percebe-se que as crenças, valores, hábitos e práticas propiciaram as bases para uma experiência social que legitima, em última instância, as formas de prática e reflexão moral e ética capazes de evidenciar os valores e normas de conduta de uma sociedade.

Essa mudança vem ao lado daquelas empreendidas pela Museologia, que desloca o foco de atuação dos museus da coleção para as relações do homem com seu patrimônio, agora cada vez mais direcionado para as práticas sociais, não somente pela sua importância comunicacional, mas, sobretudo, por serem estas o lugar de constituição relacional das representações e das práticas.

No âmbito do patrimônio, na sessão de abertura da XII Conferência Geral do ICOM (1980), o ministro do México, Pedro Ramirez-Vasquez, definiu esse novo foco dos museus ao atribuir valor moral ao "conjunto de princípios e valores espirituais que sustentam a vida da comunidade dentro de um povo e dá sentido à sua vida cotidiana" e valor de existência para o patrimônio do futuro com "a conservação do equilíbrio e dos recursos de nosso universo" que possibilita "à próxima geração uma vida melhor, em harmonia com a criação [...]". Neste discurso, o ministro reafirma o valor de existência ao declarar: "O patrimônio pode ser entendido como um processo de criação e renovação, assegurando a continuidade entre a matéria, a vida, o espaço e o tempo", portanto, ele é "inseparável do conceito de devir" (Icofom, 2000:54-55).

Contudo, no limite da ruptura, esse presente se revela incapaz de preencher o espaço aberto entre o campo da experiência e o horizonte de expectativas. Isto se revela na própria imagem da citação em epígrafe - "O passado bate à porta, o futuro na janela e o presente descobre que o solo desmorona sob seus pés" (Hartog, 1996: I39).

Dessa forma, se o presente onipresente tem dificuldades em tomar a si mesmo como sua própria avaliação, o passado surge como um campo de potencialidades para a proposição de novas questões e resposta à luz de um presente que toma em consideração a dimensão do futuro, mas que não constitui em si a dimensão última capaz de fundamentar os nossos caminhos. Portanto, as escolhas do presente precisam buscar esse solo nos diferentes pontos de vista, na contraposição de argumentos, para comparativamente buscar respostas possíveis para um futuro incerto:"É necessário encontrar uma forma de relação entre o passado e o presente, de tal modo que o passado não pretenda ditar a conduta ao presente e tampouco permaneça completamente inerte" (Hartog, 1996: 133). Nesse caso, compreendemos este "inerte" como um fardo "morto" a ser carregado, que não se vivifica no presente.

Isso nos leva a pensar em fazer escolhas à luz das condições para se falar algo sobre um passado que obedece às demandas que lhe são posteriores "uma visada retrospectiva, mesmo que com expectativas de futuro implícita ou 
explicitamente definidas" (Nicolazzi, 20 I0:235). Nesse sentido, abre-se a possibilidade de um olhar historiográfico sobre o uso desse passado pelo presente de forma mais equânime, como um quadro mais abrangente de forças e relações, valorizando a dimensão pública e política da história (Nicolazzi, 20 1 0:235236). Como esclarece González de Gómez (1995:85):

[...] preferimos o retorno a uma dialética renovada, capaz de ler, nos espaços relacionais, pontos de ruptura e trajetos irreversíveis, assim como aceitar os jogos dinâmicos do negar e do afirmar, do contínuo e o descontínuo, permitindo substituir a linha única e mestre da história pelas pluralidades simultâneas, as heterologias discursivas, as transversalidades que cruzam os planos homogêneos das lógicas sociais e culturais.

Por esse caminho, o museu se define como um "lugar" por ser "uma encruzilhada onde se encontram diferentes caminhos da memória" (Hartog, 1996:137), construídos por sua capacidade de remodelar, retomar e revisitar tempos e lugares sob a ótica das questões formuladas do presente. Um museu capaz de vivificar as questões não apenas pela elaboração de pesquisadores e especialistas, mas pela própria dinâmica de participação da sociedade. Museus como lugares de fomento da ação, mais do que seguidores dos modelos de gerações anteriores, que se voltam para o âmbito social da comunicação e concretizam seu sentido no mundo de vida (Kinard, |97|: I02).

Um museu que expõe os problemas atuais em paralelo com seus equivalentes históricos de forma a promover uma reflexão crítica capaz de subsidiar as ações no mundo. Como propõe Jorge Enrique Hardoy (1994: 2 I 3-222), museus com a missão de "criar as bases da compreensão dos problemas, para formar indivíduos responsáveis por um processo de mudanças sociais e políticas".

\section{Considerações Finais}

Nos caminhos da musealidade do patrimônio "meio ambiente" já se pode identificar a constituição de um patrimônio que se define temporal e espacialmente nas diferentes formas de conceber e viver a relação sociedade-meio ambiente. Congregando processos, estados e representações da natureza, a "Museologia de relações" instaura processos de valorização do universo relacional do objeto ao tempo em que reafirma o seu papel de gestor de um projeto de patrimônio que se ancora nas gerações futuras.

Assim, conforme proposto por Davallon et al. (1992), o museu assume seu status de protagonista e evolui sobre o campo destinado a pertencer por suas escolhas de discurso: um corpo da vida civil. Um espaço público no qual se articula o entrelaçamento dos tempos e lugares na forma de adensamentos de sentidos, contingências em torno de uma temática. Nesse caso, o tema meio ambiente torna-se um conceito integrador, o qual subsidia uma reflexão acerca dos valores sobre os quais repousa a sociedade possibilitando reconfigurar a dinâmica institucional do museu, uma vez que a relação sociedade e meio ambiente significa redistribuir as relações de força no campo museológico de forma a contemplar sua dimensão pública.

O museu passa de uma instância de consolidação de políticas públicas alicerçadas na visão de uma racionalidade de processos que fornece as informa- 
ções a um coletivo para uma importante arena política, que enfrenta as questões de interesse coletivo, propiciando mecanismos de expressão capazes de promover uma experiência da pluralidade de perspectivas que evidenciam o sentido profundo da esfera pública. Reside aí a sua importância para o patrimônio meio ambiente, um espaço público que possibilita refletir no plano metacomunicacional sobre um patrimônio em projeto englobando tudo que deve ser conservado, material ou imaterial, em função das gerações futuras.

\section{Referênciais}

ARPIN, Roland. Quelle est la vraie nature du musée. In: DAVALLON, Jean; GRANDMONT, Gerald; SCHIELLE, Bernard. L'environnement entre au Musée. Lyon: Presses Universitaires de Lyon, 1992. (Collection Muséologies)

. L'Environnement releve de La politique et de La science. In: DAVALLON, Jean; GRANDMONT, Gerald; SCHIELLE, Bernard. L'environnement entre au Musée. Lyon: Presses Universitaires de Lyon, 1992. (Collection Muséologies)

AUSTRALIAN COMMITTEE FOR IUCN. Australia Natural Heritage Charter for the conservation of places of natural heritage significance: standards and principles. Australia Heritage Commission in association with Australian Committee for IUCN. Sydney NSW, 2002.

BEZERRA, Onilda Gomes. Os valores da natureza no contexto da conservação integrada do patrimônio natural e cultural. Disponível em: <http://www.mostreseuvalor.org.br/publicacoes/index.php?pagina=6>.Acesso em: $0 \mathrm{I}$ ago. $20 \mathrm{I} 2$.

BERQUE, Augustin. Paisagem-Marca, Paisagem-Matriz: elementos da Problemática para uma Geografia Cultural. In: CORREAA, Roberto Lobato; ROSENDAHL, Zeny (Orgs.). Paisagem, tempo e cultura. Rio de Janeiro: Ed Uerj, 2004.

BORGES, Luiz C. ; CAMPOS, M. D'Olne . Patrimônio como valor, entre ressonância e aderência. In: SCHEINER, Teresa C.M.; GRANATO, Marcus; REIS, Maria Amélia G. de Souza; BARRIOS AMBROCY, Gladis. (Orgs.). Termos e conceitos da museologia: museu inclusivo, interculturalidade e patrimônio integral. I. ed. Rio de Janeiro: MAST/UNIRIO, 20I2, v. I, p. I I 2-I 23.

BRASIL. Constituição (1988). Constituição da República Federativa do Brasil. Brasília, DF, Senado, 1998.

BRASIL, MMA. A Convenção sobre Diversidade Biológica - CDB, Decreto Legislativo $\mathrm{n}^{\circ} 2$, de 5 de junho de 1992. MMA. Brasília, 2002.

CHOAY, Françoise. A alegoria do patrimônio.Tradução de Luciano Vieira Machado. São Paulo: Estação Liberdade: Editora da Unesp, $200 \mathrm{I}$.

COMISSÃO MUNDIAL SOBRE MEIO AMBIENTE E DESENVOLVIMENTO. Nosso futuro comum. 2. ed. Rio de Janeiro: Editora da Fundação Getulio Vargas, 1991.

DAVALLON, J. ; GRANDMONT, Gerald ; SCHIELLE, Bernard. L'environnement entre au Musée. Lyon: Presses Universitaires de Lyon, 1992. (Collection Muséologies) 
DECAROLIS, Nelly. Patrimonio tangible e intangible, Un delicado equilibrio: junho de 200I.Disponível em: <http://www.ilam.org/ILAMDOC/sobi/Decarolis_Patrimonio\%20tangible\%20e\%20intangible-Pat.pdf >.Acesso em: 20 mar. 2012.

DORFMAN, Eric; CARDING, Janet. Towards a unified concept of intangible natural heritage. In: Intangible natural heritage: New Perspectives on Natural Objects. London: Routledge, 20 I I.

GONÇALVES, José Reginaldo. "O patrimônio como categoria do pensamento: ensaios Contemporâneos”. In:ABREU, Regina; CHAGAS, Mário (Orgs.). Memória e patrimônio. 2. ed. Rio de Janeiro: Lamparina, 2009.

GONZALEZ DE GOMEZ, Maria Nélida. A informação: dos estoques às redes. Ciência da Informação, v. 24, n. I, 1995. Disponível em: <http://revista.ibict.br/ ciinf/index.php/ciinf/article/view/533/485>.Acesso em: I 2 set.20I 2.

HARDOY, Jorge Enrique. "Progrès ou croissance?" [1974]. In : DESVALLÉES, André. Vagues: une anthologie de la nouvelle museologie. Paris: W M. N. E. S., 1994, v.2. p.213-222.

HARTOG, François. Tempo e patrimônio. Belo Horizonte: Varia Historia, v. 22, n.36, jul./dez. 2006, p.26I-273.

.Tempo e história: “Como escrever a história da França hoje?”. História Social. Campinas/SP, n.3, 1996, I27-I54.

O tempo desorientado. Tempo e história. "Como escrever a história da França?". Anos 90, Porto Alegre, PPG em História da UFRGS, n. 7, julho 1997.

ICOFOM LAM. Carta de Cuenca. Encuentro del comitê regional para a américa latina y caribe / ICOFOM LAM. Cuenca [Ecuador]. In: El pensamiento museológico latinoamericano - los documentos del ICOFOM LAM/ compilados por Nelly Decarolis. Córdoba: ICOFOM LAM, 2006, p. 38-44.

ICOMOS. Carta de Burra (1999). Disponível em: < http://www.international.icomos.org/charters/burral999_spa.pdf>.Acesso em:06 jun. 2015.

KINARD, John. "Intermédiaires entre musée et communauté” [197I]. In: DESVALLÉES, André. Vagues: une anthologie de la nouvelle museologie. Paris:W M. N.E.S., 1994, v. 2. p. 102.

LÉVY, Pierre. O que é o virtual? São Paulo: Ed. 34, 1996.

LIMA, Diana Farjalla Correia. Museologia-Museu e Patrimônio, Patrimonialização e Musealização: ambiência de comunhão. Boletim do Museu Paraense Emílio Goeldi. Ciências Humanas, v. 7, n. I, p. 3I-50, jan.-abr. 2012.

MENESES, Ulpiano T. Bezerra de. O campo do patrimônio cultural: uma revisão de premissas. In: I Fórum Nacional do Patrimônio Cultural: Sistema Nacional do Patrimônio Cultural: Desafios, estratégias e experiências para uma nova gestão, 2012, Ouro Preto/MG, 2009. Brasília: IPHAN, 2009. v. I, p. 25-40.

NICOLAZZI. Fernando. A História Entre Tempos: François Hartog $E$ A Conjuntura Historiográfica Contemporânea. História: Questões \& Debates, Curitiba, n. 53, p. 
229-257, jul./dez. 2010. Editora UFPR.

SAUVÉ, Lucie. Perspectivas curriculares para la formación de formadores en educación ambiental. Conférence présentée dans le cadre du Primer Foro Nacional sobre la Incorporación de la Perspectiva Ambiental en la Formación técnica y profesional. Du 9 au 13 juin, 2003, Universidad Autonoma de San Luis Potosi, Mexique, 2003. 20 pages (CD-Rom non paginé; http://ambiental.uaslp.mx/foros/p/cd/).

SCHEINER, Tereza. Repensando o Museu Integral: do conceito às práticas. Boletim do Museu Paraense Emílio Goeldi. Ciências Humanas, Belém, v. 7, n. I, p. I5-30, jan.-abr. 2012

SOARES, B. C. B. Resenha - O meio ambiente entra no museu. Revista Eletrônica Jovem Museologia. Estudos sobre Museus, Museologia e Patrimônio, vol. 3, n. 5. I/2008. p. I08-I I I. ISSN: 1980-6345.

UNESCO. Representação da Unesco no Brasil. Com o Rio, Brasil passa a ter 19 sítios na Lista do Patrimônio Mundial da Unesco. 02/07/2012. Disponível em: <http://www.unesco.org/new/pt/brasilia/about-this-office/single-view/news/rio_ becomes_the_19th_brazilian_site_in_the_world_heritage_list_of_unesco/>. Acesso em: 20 ago. 2012.

UNESCO. Convenção para a protecção do património mundial, cultural e natural (1972). Disponível em: < http://whc.unesco.org/archive/convention-pt.pdf>. Acesso em: 06 jun. 2015.

Artigo recebido em julho de 20I5. Aprovado em agosto de 2015 